\section{Conceptualizing Problem-Based Learning: Ensuring Realization of Curriculum Intentions}

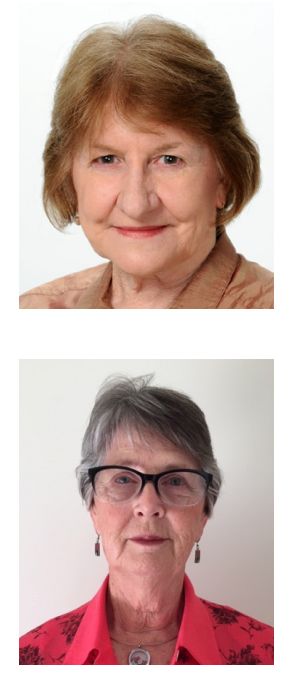

Margaret McMillan

School of Nursing and Midwifery, University of Newcastle, Australia

Penelope Little

School of Nursing and Midwifery, University of Newcastle, Australia

Savin-Baden in this edition of the journal argues there is a lack of definition and differentiation in the models of Problem-based Learning (PBL) in use globally and therefore PBL is not delivering on its potential to produce wise learners who value uncertainty and different ways of knowing, challenge the status quo, and bring about transformational change in themselves and society. She postulates that this has come about as a consequence of the practice of "tracing" other models of PBL without critically examining the discipline and cultural context of the curricula. She also argues that the current emphasis on quality assurance and risk management in Higher Education, together with curricula bound by templates and knowledge and skills-based outcomes, result in restrictive and repressive curricula.

Instead, Savin-Baden proposes that PBL should not be defined as a "method" but as a set of concepts and principles that leads to a pedagogy that promotes wisdom, uncertainty, and ecologies of learning that encompass "co-construction of meaning, deconstruction of knowledge and learning spaces that are both formal and informal". The concepts of liminal tunnels where learning results in transformation of self as a person, professional or learner is also central to her thinking. However, the final concept of "PBL as constellations" provides a way of describing different approaches used in PBL that provide flexibility and could inform design and implementation decisions when aspiring to and applying creativity and developing a context specific PBL curriculum.

Finally, Savin-Baden offers a set of practices for the rethinking of curriculum making as "assemblage": Mustering, folding and mapping; and consideration of the key questions:

What knowledge is of most worth?

What might a flexible curriculum look like?

Should we consider facilitators as fools?

Savin-Baden has indeed provided a paper to challenge the conventional wisdom, invite us as curriculum developers to think outside the boxes, be creative and transformational, that is to apply the concepts of PBL to our curriculum development endeavours. She mentions

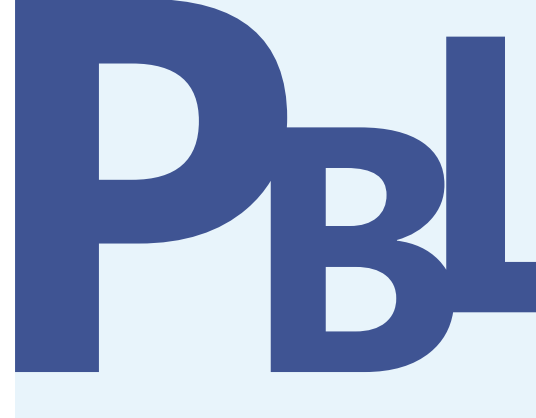

\section{Editorial}

pISSN 2288-8675 · elSSN 2508-9145

J Probl Based Learn 2020;7(1):1-2

https://doi.org/10.24313/jpbl.2020.00234

Received: April 27, 2020

Accepted: April 29, 2020

Corresponding author:

Margaret McMillan

School of Nursing and Midwifery,

University of Newcastle, 66 Rickard

Street, Bateau Bay, NSW 2261,

Australia

Tel: +61-408-431269

E-mail:margaret.mcmillan@

newcastle.e du.au
(C) Copyright 2020 International Society for Problem-Based Learning

(c) This is an Open Access article distributed under the terms of the Creative Commons Attribution Non-Commercial License (http://creativecommons.org/licenses/ by-nc/4.0/) which permits unrestricted non-commercial use, distribution, and reproduction in any medium, provided the original work is properly cited. 
Stenhouse's (1975) focus on curriculum intentions; by this she is alluding to his reference to society's beliefs about the sort of individual that is valued within the community. She highlights the learning processes; these she suggests are paramount in accommodating creativity in the learning journey. Hence the role of the facilitator is crucial in managing learning processes rather than functioning as a content expert. By suggesting that facilitators need to be regarded as 'fools' in the Shakespearian sense ie "wise fools" who "are used to comment on society and to present a different world view", she seems to be highlighting the enormity of the change required in the demeanour and style of the manager of learning situations if they are to fulfil the role of provocateur. Individual teachers will have their own 'style', but all members of a team need to appreciate what changes they are trying to produce in their students.

Given our aspirations for PBL as transformative learning, it is important to question the rationales for our own decisions and ask whether we are using the philosophical underpinnings of PBL to liberate learners and teachers on their quest for greater creativity. How do the curriculum development team members ensure that the needs of learners remain central to their thinking? How does one also make decisions as suggested by Stufflebeam (2003) on matters related to the context of education and the relevant professional practice, all the features of design or input, good governance of the implementation process that does not stifle aspirations for creativity and finally that the product (graduate outcomes) match the intent (goals)of the program.

Learners and teachers are only two of a number of stakeholders (Weiss, 1983) in the curriculum design and implementation processes. Other decision-makers or people who are impacted by decisions on processes and outcomes, for example in health services these include representatives from regulatory, industrial and professional bodies, health care providers as prospective employers and consumers, either as learners or others as recipients of professional care. There are also a number of 'hurdles' to overcome as we meet 'prescribed standards' within the internal and external processes of curriculum approval. Different stakeholders will have different 'concerns' on which to focus. Raising and addressing any of these concerns has the potential to confound aspirations for creativity.

In our experience, addressing concerns of all stakeholders often has the potential to add value to the curriculum design and outcomes. However, the key to mutual understanding of 'intentions' derives from a willingness to find ways of ensuring that we can actually demonstrate elements and outcomes within the student experience of both learning and practice. Hence existing students and graduates play a key role in accreditation processes. They are central to modelling outcomes of curriculum processes. At the time of curriculum accreditation and review, showcasing actual learning processes has the potential to demonstrate PBL concepts and principles in action. In our experience the student/ graduate who confidently and competently responds to questions and asks more questions in return is the student who is more likely to safely respond to novel situations in actual practice; they have fully embraced the enquiry and lifelong learning processes that are central to PBL.

\section{REFERENCES}

Stenhouse, L. (1975). An introduction to curriculum research and development. London: Heinemann.

Stufflebeam, D. (2003). The CIPP model of evaluation. In T. Kellaghan, D. Stufflebeam \& L. Wingate (Eds.), Springer international handbooks of education: International handbook of educational evaluation. Dordrecht: Springer.

Weiss, C.H. (1983). The Stakeholder approach to evaluation: Origins and Promise. In New Directions in Program Evaluation. Stakeholder-based Evaluation Issue, 1983, 3-14. 